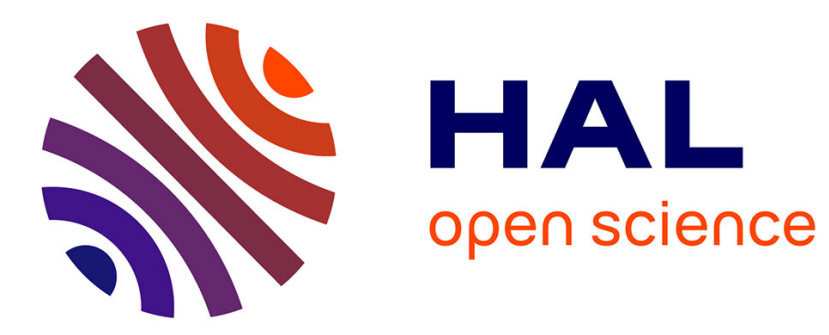

\title{
Adaptive meshing for the boundary integral equation method: Definition and test of an error estimator
}

Bidjan Haghi-Ashtiani, Laurent Krähenbühl, Alain Nicolas

\section{To cite this version:}

Bidjan Haghi-Ashtiani, Laurent Krähenbühl, Alain Nicolas. Adaptive meshing for the boundary integral equation method: Definition and test of an error estimator. IEEE Transactions on Magnetics, 1998, 34 (5 Part 1), pp.3443-3446. hal-00140674

\section{HAL Id: hal-00140674 https://hal.science/hal-00140674}

Submitted on 20 Apr 2007

HAL is a multi-disciplinary open access archive for the deposit and dissemination of scientific research documents, whether they are published or not. The documents may come from teaching and research institutions in France or abroad, or from public or private research centers.
L'archive ouverte pluridisciplinaire HAL, est destinée au dépôt et à la diffusion de documents scientifiques de niveau recherche, publiés ou non, émanant des établissements d'enseignement et de recherche français ou étrangers, des laboratoires publics ou privés. 


\title{
Adaptive Meshing for the Boundary Integral Equation Method: Definition and Test of an Error Estimator
}

\author{
Bidjan Haghi Ashtiani, Laurent Krähenbühl, Alain Nicolas
}

Centre de Génie Électrique de Lyon - UPRESA CNRS 5005 - ECL, BP 163, 69131 Ecully Cedex (France)

\begin{abstract}
During last years, numerous authors have developed adaptive meshing methods based on efficient error estimators for the Finite Element Method. In this paper we propose a similar tool, meant expressly for the Boundary Integral Equation Method (BIEM). We will first present the expression of the proposed error estimator, then analyze its properties in the context of a specific BIE program and for a simple electrostatic structure. We present finally the implementation of this estimator in association with novel techniques for adaptive meshing.
\end{abstract}

Index terms - Boundary Integral Equation Method, adaptive meshing, error control, iterative solver, electrostatics.

\section{INTRODUCTION}

In comparison with the Finite Element Method (FEM), the Boundary Integral Equation Method (BIEM) offers important advantages to solve linear field problems. Particularly, a surface description of the modeled objects is sufficient. In return, the BIEM matrix is full and moreover generally illconditioned : then direct-solvers have to be used. It follows very high computation costs : the BIEM seems limited to rather simple applications.

In this paper, we propose some trails, which will probably allow to extend the field of the BIEM : adaptive meshing with accuracy control (the mesh is refined only where it is useful), associated to a technique of non-connected mesh allowing very high variations of the mesh density, and to a technique of local solution refinement, which avoids to solve the complete linear system for each mesh step. Moreover, this local solver could in the future run into a real iterative solver for the BIEM matrices.

We will here only consider electrostatics (BIEM Green's formulation [2]), but the proposed method is also valid for other applications or formulations of the BIEM. Our tests will be done on a simple benchmark problem (Fig. 1), including various boundary conditions (Dirichlet on the upper cube, dielectric boundary on the lower cube). In principle, the mesh has to be denser along the angles of the upper cube, and on

Manuscript received November 3, 1997.

L. Krähenbühl : krahenb@trotek.ec-lyon.fr

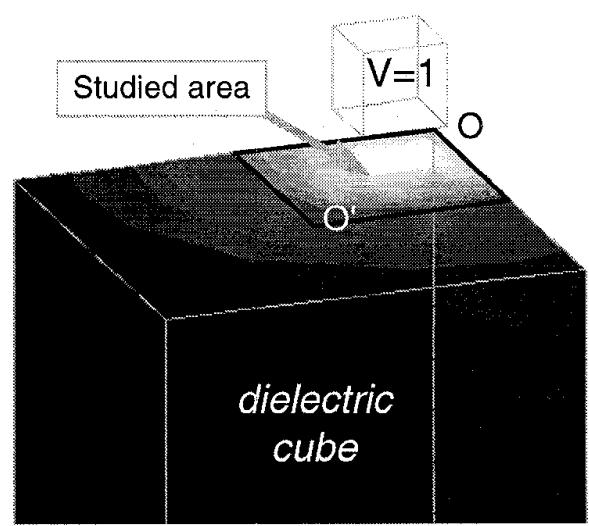

Fig. 1 : Test Problem and location of the test-area

the studied area of the lower cube. For $\varepsilon_{\mathrm{r}}=1$ in the lower cube, the (quasi) exact solution can be determined on it : this allows very accurate testings

\section{BIEM FORMULATION}

From Green's theorem and Laplace's equation we get:

$$
\Omega_{S}(P) \cdot V(P)=\underbrace{-\oint\left(\left.V(Q) \cdot \frac{\partial G_{P}}{\partial n}\right|_{Q}-\left.\frac{\partial V}{\partial n}\right|_{Q} \cdot G_{P}(Q)\right) \cdot d s}_{F_{S}(P, V, \partial V / \partial n)}
$$

$\mathrm{S}$ : surface of the studied domain

$\Omega_{\mathrm{S}}(\mathrm{P})$ : solid angle from $P$ to $S$

$$
\mathrm{G}_{\mathrm{p}}(\mathrm{Q})=\frac{1}{4 \pi \mathrm{PQ}}: \text { Green's function }
$$

\section{$\mathrm{V}$ : electric potential}

This equation is valid for each point $\mathrm{P}$ (inside, on, or outside $\mathrm{S}$ ), if the correct value is assigned to the solid angle $\Omega$. To solve numerically this Boundary Integral Equation, we have to discretize the potential $\mathrm{V}$ and its normal derivative using a surface finite element mesh:

$$
\left\{\begin{array}{l}
\tilde{V}[P(u, v)]=\sum_{j} \alpha_{j}(u, v) \cdot V_{j} \\
\tilde{V}^{\prime}[P(u, v)]=\left.\sum_{k} \alpha_{k}(u, v) \cdot \frac{\partial V}{\partial n}\right|_{k}
\end{array}\right.
$$




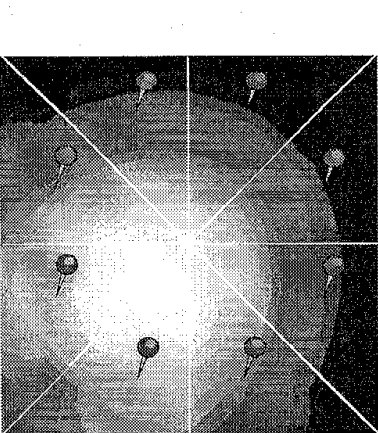

integral value $\mathrm{F}_{\mathrm{s}} / \Omega_{\mathrm{s}}$<smiles>[CH][AsH2]</smiles>

Fig. 2: Example of potential values on the test area (Fig. 1) in respect of the same solution.

and to search for the best values of $V_{j}$ and $\left.\partial_{n} V\right|_{k}$. The solution must set the discrete value $\tilde{V}$ of $\mathrm{V}$ nearer to its integral value $\mathrm{F}_{\mathrm{s}}$;

$$
\Omega_{\mathrm{S}}(\mathrm{P}) . \tilde{\mathrm{V}}(\mathrm{P}) \rightarrow \mathrm{F}_{\mathrm{S}}\left(\mathrm{P}, \tilde{\mathrm{V}}, \tilde{\mathrm{V}}^{\prime}\right) \quad \forall \mathrm{P} \in \mathrm{S}
$$

The point collocation method ([2], Fig. 2) is the simplest way to obtain this result: the two values of $\mathrm{V}$ are equalized on as many points on $\mathrm{S}$ as there are unknown coefficients in $\tilde{\mathrm{V}}$ and $\tilde{\mathrm{V}}^{\prime}$ (the corresponding matrix is dense and nonsymmetric; a direct method is used for solving the linear system).

\section{ERROR FUNCTION}

We propose to define the following error function $[3,4]$ :

$\mathrm{E}_{\mathrm{S}}\left(\mathrm{P}, \tilde{\mathrm{V}}, \tilde{\mathrm{V}}^{\prime}\right)=\left[\Omega_{\mathrm{S}}(\mathrm{P}) . \tilde{\mathrm{V}}(\mathrm{P})-\mathrm{F}_{\mathrm{S}}\left(\mathrm{P}, \tilde{\mathrm{V}}, \tilde{\mathrm{V}^{\prime}}\right)\right] /\left(\mathrm{V}_{\max }-\mathrm{V}_{\min }\right)(4)$

This function (defined for $P \in S$ ) vanishes on every collocation points (Fig. 2,3), and oscillates near zero between these points. We will discuss the use of this function as error estimator in a process of adaptive meshing: Figures 3 and 4 make already visible the link between the mesh refinement, the mean value of $E_{S}$ and the accuracy of the solution.

\section{IMPLEMENTATION}

A. Discretization. In the 3D-BIEM program used to test this error function, we did following choices concerning discretization:

- the surface is meshed using first order triangles: the use of plan facets makes the computation of singular integrals easier, and triangles facilitate the local mesh refinements.

- the surface electric potential is discretized using first order weighted functions (that is the lowest order which ensures the continuity of potential).
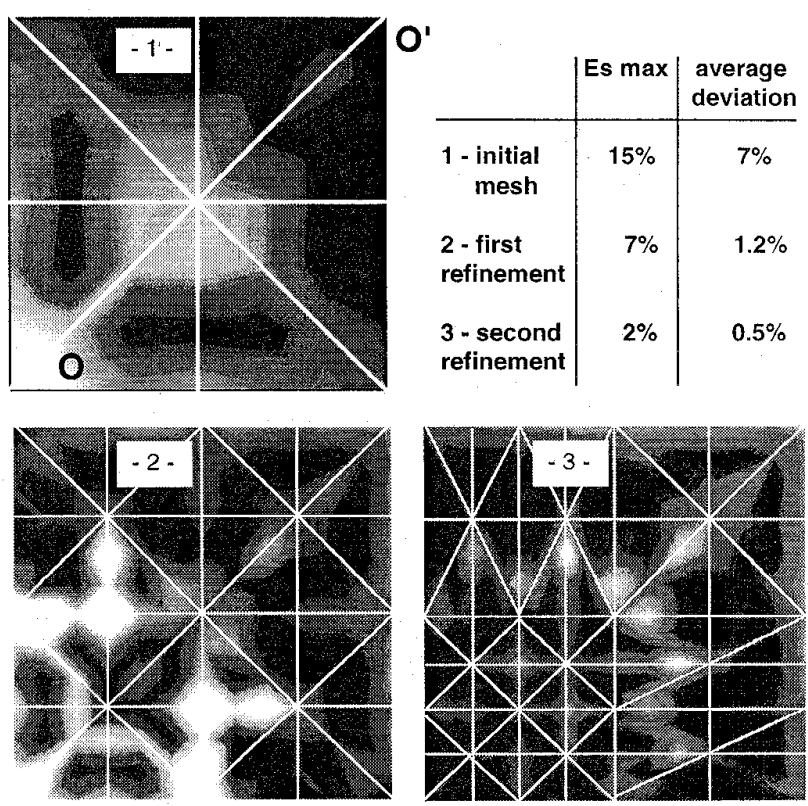

Fig. $3: E_{S}$ on the test-area as function of the mesh refinement

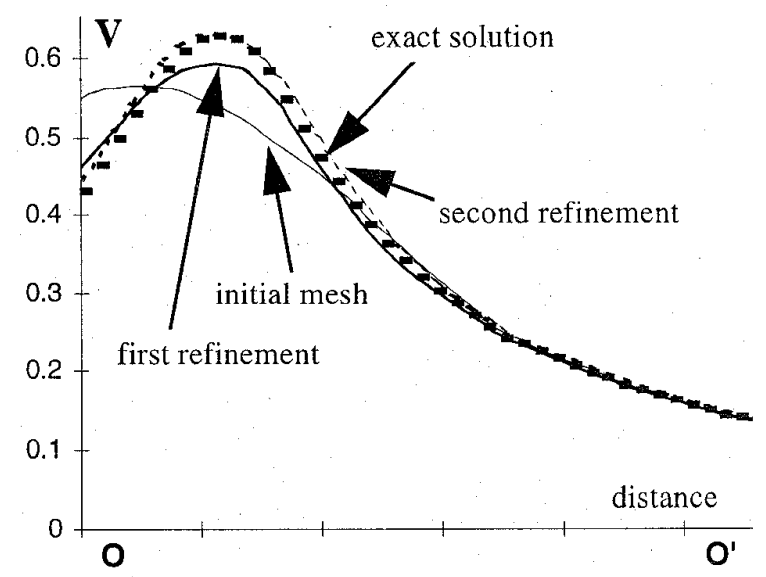

Fig. 4: Solution $V$ on line OO' (Fig. 1) for the different mesh refinements

- the normal derivative of $\mathrm{V}$ is supposed constant on each triangle: this choice is coherent with precedent, and it makes the analytic computation of integrals (1) possible. It permits also to skip the question of discontinuities on angles and corners.

B. Numerical integration. The linear BIE system is built by writing (3), either on every node of the surface mesh (if $\widetilde{V}$ is unknown) or on the center of gravity of every triangle (if the normal derivative $\widetilde{V}^{\prime}$ is unknown). For a boundary between two dielectric media, neither $\tilde{V}$ nor $\tilde{V}^{\prime}$ are known and (3) has to be written on nodes for the first side (boundary 
of the first dielectric medium) and on centers of gravity for the other.

To get pertinent values of $E_{S}$ (after resolution of the BIE), it is necessary to be able to calculate the surface integral $F_{S}(P)$ on any point $\mathrm{P}$ of every triangles (not only on the mesh-nodes or on the centers of gravity). Now, basic integrants in (1) are singular : we compute it using the best methods found in the literature $[5,6]$.

- for the Green's function, related to the normal field V'(zero-order), analytic results will be used close to the element, and Gaussian one-point integration farther;

- For the solid-angle, related to the potential V, we use Gaussian multi-points integration, with eventually a recurrent cupping up of elements ${ }^{1}$ (depending on the relative distance to the element).

In all cases, these techniques make the numerical errors on $F_{S}$ very lower as $E_{S}$.

\section{ESTIMATION OF ES AND VALIDATION}

The decision to refine (or not) a given triangle depends on the extreme values of $\left|E_{S}\right|$ on this triangle. To find this maximum, we have normally to compute $F_{S}$ on numerous points of the triangle (Fig. 3). In practice, it is possible to define a priori a few strategic points, which give sufficient information (has this triangle to be refined, or not ?), but at a lower cost: we have carry out numerous tests, and we concluded that statistically good results are obtained on nodes when the collocation points are the center of gravity of elements, and reciprocally.

This fact can be verified from the results corresponding to the meshes of Fig. 3, which are synthesized on Fig: $5:$ each point on this figure presents this estimation $\hat{\mathrm{E}}_{\mathrm{S}}$ of the maximal value of $\mathrm{E}_{\mathrm{S}}$, as function of the real maximum of $\mathrm{E}_{\mathrm{S}}$, on a given element. Obviously, the statistic correlation is excellent for the elements of the three successive meshes of the test area.

For this test, the relative permittivity of the dielectric cube was set to one : the (quasi) exact solution for the lower cube can be obtained by solving the BIE only on the upper cube. Then, it is possible to compare the values of the estimator $E_{S}$ with the real error, for each element of the test area. Figure 6 presents the correlation for the 3 meshes: this constitutes an experimental validation of $E_{S}$ as an error estimator for the BIEM.

\footnotetext{
1 A maximum number of subdivisions is a priori defined; farther, the integrant is supposed constant on the last sub-element.

2 It could happen that a «bad » element is not detected. During our tests, we observed that such an element was always detected during the next step of the adaptive mesh generation.
}

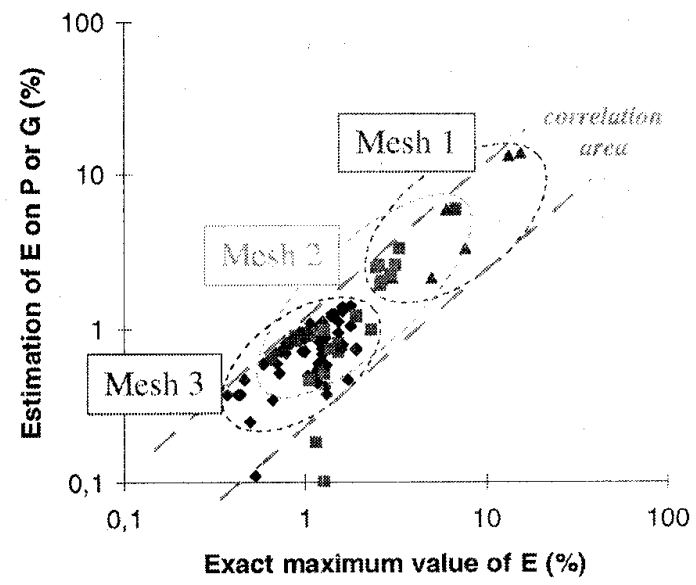

Fig. 5: Estimation of the maximum of $\mathrm{E}_{\mathrm{S}}$ on each element

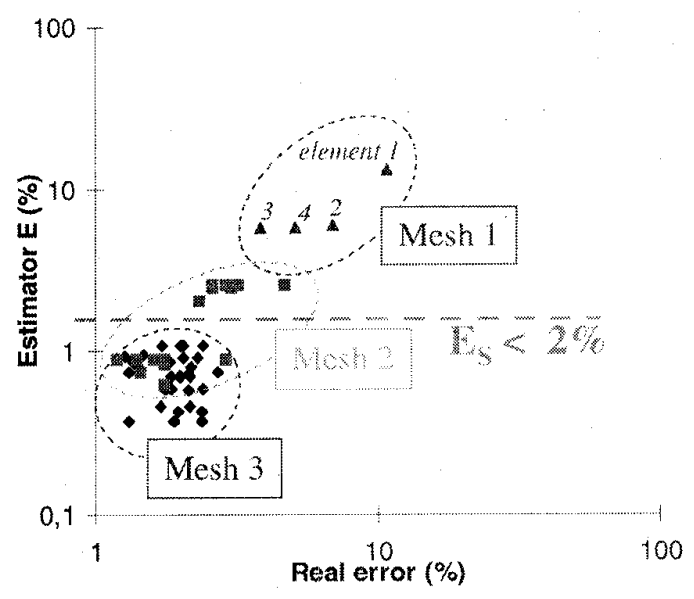

Fig. 6: Comparison between $\hat{\mathrm{E}}$ and the real error

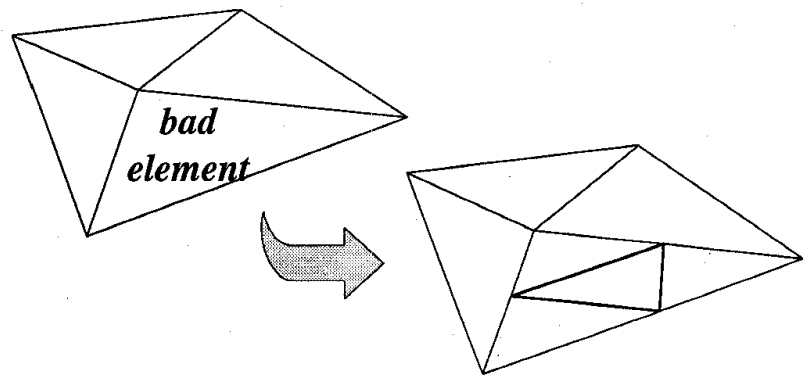

Fig. 7 : Subdivision of a « bad » element

\section{MESH REFINMENT AND LOCAL SOLUTIONS}

To test this error estimator, we implemented it in a process of adaptive meshing for BIEM. We start with a minimum mesh of the studied structure. After resolution, $\hat{E}_{S}$ is calculated for each element. If this error estimator is greeter than a given level ( $2 \%$ in our examples), we subdivide the element, according to Fig. 7. Another resolution is linked, and 
so on, until $\hat{E}_{\mathrm{S}}$ is less than the fixed limit value on all the elements

In comparison with the classical techniques of adaptive meshing, used in particular with finite elements [1], our way presents two particularities :

- we do not search to get a «conformable » mesh by propagating the subdivisions (Fig. 6). So it is possible to obtain very high variations of the mesh density, which minimizes the number of unknowns. Of course, this leads to discontinuous values of $\tilde{V}$ on the boundary between two non conformable elements, but this is not a priori unfavorable : this does not prevent to compute exactly the integral form (1), and this provides an additional error estimator (based on the value of the jump of potential along this boundary $)^{3}$.

- In theory, the full BIE problem has to be solved again after each mesh refinement and the total CPU-time becomes steeply too high. In fact, the solution on nodes which are « far from » the refinement area is «not very » modified. Then, to save on computation time, we have successfully tested local resolutions (Fig, 8): for each step of the process of adaptive meshing, the values of $\mathrm{V}$ and $\mathrm{V}^{\prime}$ are kept, except for the elements which have just been subdivided.

The approximate solution for the final mesh could be improved by using such recurrent local resolutions (iterative scanning of the geometry). So we expect to obtain a real iterative solver for the BIE. However, the example below proves that simple local resolutions give already a wonderful accuracy (Fig. 9).

\section{CONCLUSION}

In this paper, an error estimator for the boundary integral equation method is proposed. The good correlation with the real error is shown in a simple electrostatic case.

The implementation is presented in a process of adaptive mesh generation, which calls on techniques of non conformable elements and local resolutions, to save on CPUtime. These techniques could shortly lead to an iterative method efficient to solve the linear systems stemming from the BIEM.

In principle, the error estimation is not limited to electrostatics, and a similar estimator could be developed for all the applications of the BIEM.

\footnotetext{
3 By the fact; the degree of non conformability can be controlled. If necessary, the adjacent element will be divided.
}
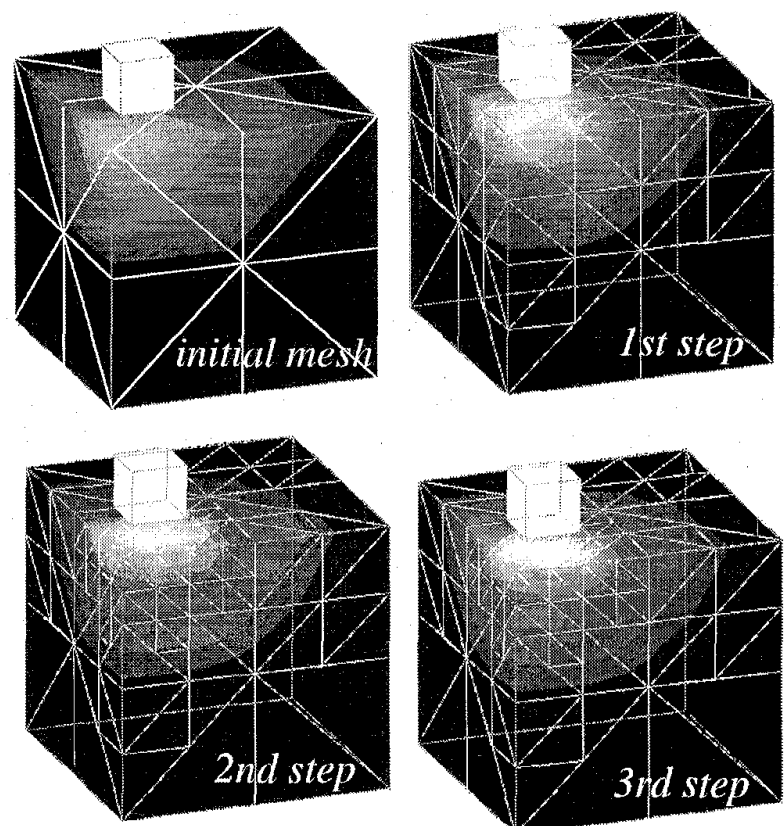

Fig. 8 : solution refinement using non conformable subdivisions of elements and local resolutions of the BIE linear system
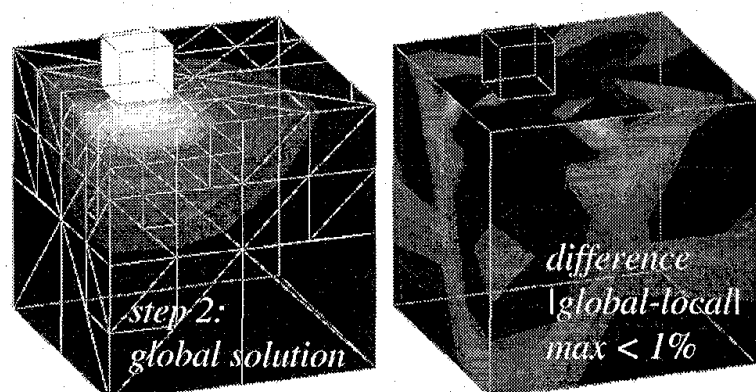

Fig. 9 : comparison between the exact (global) BIEM solution for step 2 and the local solution of Fig. 8 .

REFERENCES

[1] See for example: Compumag'95, Berlin, session "adaption and mesh generation," IEEE T-Mag. 32, number 3, Part I, pp. 1354-1372.

[2] C.A. Brebbia: The boundary element method for engineers, Pentech Press, London, 1990.

[3] L. Krähenbühl: La méthode des équations intégrales de frontière pour la résolution des problèmes de potentiel en électrostatique, et sa formulation axisymétrique, Ph-D. Thesis, E.C.L., France, 1983.

[4] Adaptive Finite and Boundary, Element Methods - Edited by C.A. Brebbia and M.H. Aliabadi, Elsevier Applied Science, London New York, 1993.

[5] Sadasiva M. Rao, Allen W. Glisson, Donald. R. Wilton, B. Sarma Vidula: "A simple numerical solution procedure for statics problems involving arbitrary-shaped surfaces," IEEE Trans. on Antennas and Propagation, Vol. 27, number 5, Sept. 1979.

[6] J. A. Vásconcelos, L. Krähenbühl, L. Nicolas, A. Nicolas : "Potential and electrical field computation at points interior to a domain using the boundary element method," International workshop on electric and magnetic field computation, Mons, Belgique, Sept. 1992. 